\title{
Effects of blue pulsed light on human physiological functions and subjective evaluation
}

\author{
Tetsuo Katsuura ${ }^{1 *}$, Yukifumi Ochiai ${ }^{1}$, Toshihiro Senoo ${ }^{2}$, Soomin Lee ${ }^{1,3}$, Yoshika Takahashi ${ }^{1}$ \\ and Yoshihiro Shimomura'
}

\begin{abstract}
Background: It has been assumed that light with a higher irradiance of pulsed blue light has a much greater influence than that of light with a lower irradiance of steady blue light, although they have the same multiplication value of irradiance and duration. We examined the non-visual physiological effects of blue pulsed light, and determined whether it is sensed visually as being blue.

Findings: Seven young male volunteers participated in the study. We placed a circular screen (diameter $500 \mathrm{~mm}$ ) in front of the participants and irradiated it using blue and/or white light-emitting diodes (LEDs), and we used halogen lamps as a standard illuminant. We applied three steady light conditions of white LED (F0), blue LED + white LED (F10), and blue LED (F100), and a blue pulsed light condition of a 100- $\mu$ s pulse width with a 10\% duty ratio (P10). The irradiance of all four conditions at the participant's eye level was almost the same, at around $12 \mu \mathrm{W} / \mathrm{cm}^{2}$. We measured their pupil diameter, recorded electroencephalogram readings and Kwansei Gakuin Sleepiness Scale score, and collected subjective evaluations. The subjective bluish score under the F100 condition was significantly higher than those under other conditions. Even under the P10 condition with a $10 \%$ duty ratio of blue pulsed light and the F10 condition, the participant did not perceive the light as bluish. Pupillary light response under the P10 pulsed light condition was significantly greater than under the F10 condition, even though the two conditions had equal blue light components.
\end{abstract}

Conclusions: The pupil constricted under the blue pulsed light condition, indicating a non-visual effect of the lighting, even though the participants did not perceive the light as bluish.

Keywords: Blue pulsed light, LED, Non-visual effect, Pupillary light response, Subjective evaluation

\section{Introduction}

Recently, quite a few studies in the field of physiological anthropology have focused on the non-visual effects of illumination on humans [1-5], with findings such as increased sympathetic nervous activity and improved arousal level, which are generally seen in response to high-color-temperature illumination that contains a rich short-wavelength light.

In 2002, intrinsically photosensitive retinal ganglion cells (ipRGCs), a novel type of photoreceptor cell, were found in the mammalian retina [6]. Researchers found that ipRGCs affect the suprachiasmatic nucleus and act as the primary photoreceptor for non-visual effects, such

\footnotetext{
* Correspondence: katsu@faculty.chiba-u.jp

${ }^{1}$ Graduate School of Engineering, Chiba University, Chiba, Japan

Full list of author information is available at the end of the article
}

as the suppression of pineal melatonin synthesis $[7,8]$ and pupillary constriction [9-14]. It was also found that ipRGCs respond to short-wavelength light of around $480 \mathrm{~nm}$ (blue light) [6,15].

Although the density of ipRGCs in the retina is much lower than that of rods or cones, resulting in a very low photon catch, each captured photon elicits a large and extraordinarily prolonged response [16]. It was reported that the contribution of ipRGCs to the pupillary light response was greater at a higher irradiance, with the role of the rods being more dominant at a lower irradiance level $[9,12,14]$. Because of this characteristic of ipRGCs, it was assumed that the light condition with higher irradiance of pulsed blue light had a much greater influence than that of the light condition with lower irradiance of steady blue light, although the two conditions had the same multiplication value of irradiance and

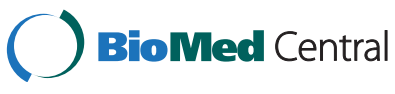

(c) 2012 Katsuura et al.; licensee BioMed Central Ltd. This is an Open Access article distributed under the terms of the Creative Commons Attribution License (http://creativecommons.org/licenses/by/2.0), which permits unrestricted use, distribution, and reproduction in any medium, provided the original work is properly cited. 

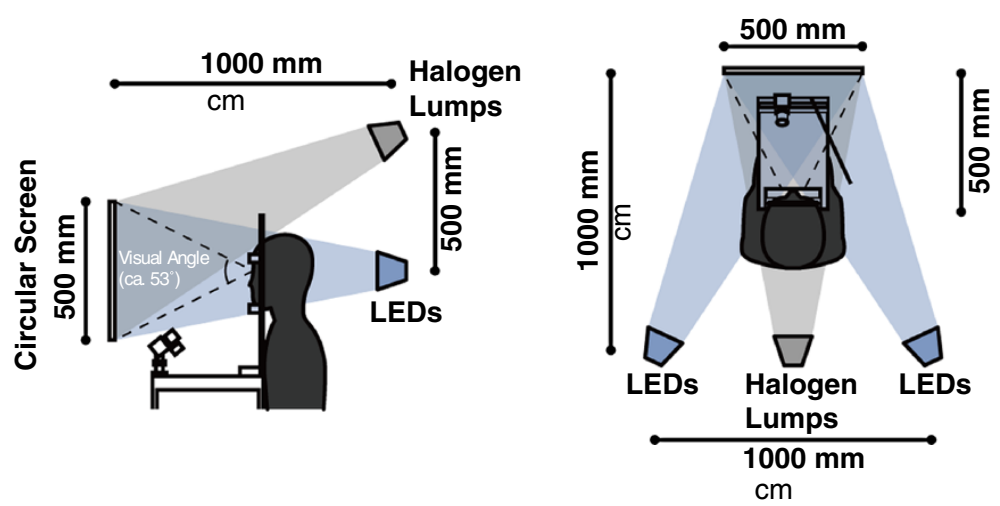

Figure 1 Experimental configuration.

duration. There have been no studies on the non-visual effect of blue pulsed light, including on the pupillary response.

The purpose of this study was to clarify the visual and non-visual features of blue pulsed light by examining the physiological functions and subjective impressions under several lighting conditions, including pulsed and steady lighting of blue light-emitting diodes (LEDs).

\section{Methods}

Seven healthy young male Japanese volunteers $(22 \pm 0.7$ years old) with dark eyes participated in the study. They were screened for normal color vision, using the Farnsworth Munsell 100 Hue Test. Each participant gave his informed consent to participate in the study. The Ethics Committee of the Graduate School of Engineering, Chiba University approved the protocol of the study. The experiment was conducted in a climatic chamber (TBR-6HA4G2C; ESPEC Corp., Osaka, Japan) in which the air temperature and

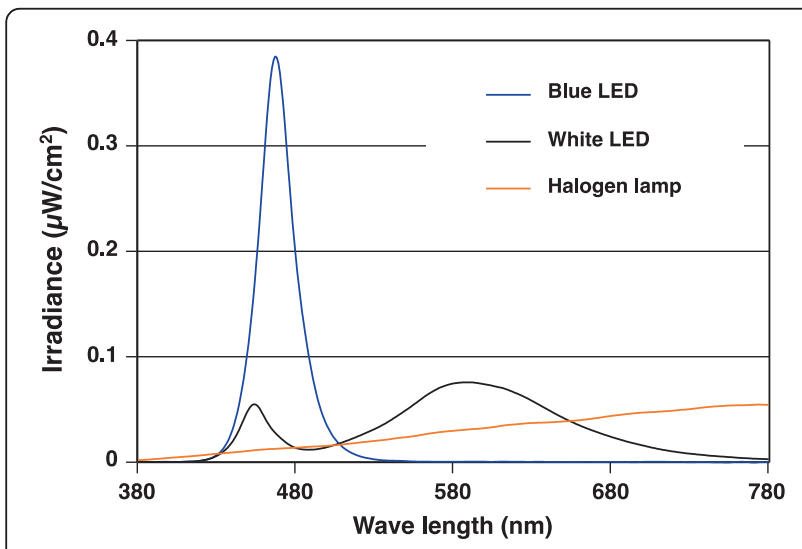

Figure 2 Spectral irradiance of blue light-emitting diodes, white light-emitting diodes and a halogen lamp. Spectral irradiance of blue light-emitting diodes and white light-emitting diodes correspond to those of the F100 condition and F0 condition. relative humidity were set at $26^{\circ} \mathrm{C}$ and $50 \%$, respectively. Each participant sat on a chair with his head fixed on a positioner $500 \mathrm{~mm}$ from a circular screen $500 \mathrm{~mm}$ in diameter. We irradiated the circular screen using blue LEDs (NS6B083T-W; Nichia Corp., Anan, Japan) and white LEDs (NS6L183T-H3; Nichia Corp., Anan, Japan), and we used a halogen lamp as a standard illuminant (Figure 1). The correlated color temperature of the halogen lamp was 3,114 K, and that of the white LED was 3,034 K.

We applied four light conditions, of which three were steady and one was pulsed. The three steady light conditions were white LEDs (F0), blue and white LEDs (F10), and blue LEDs (F100). The pulsed light (P10) was blue LEDs with a $100-\mu$ s pulse width in a square waveform plus white LEDs. The time ratio of the blue LED lighting was $10 \%$ of the duty ratio, that is, the blue LEDs were turned on for $100 \mu \mathrm{s}$ and the white LEDs were turned on for $900 \mu$ s alternately for every $1,000-\mu$ s interval.

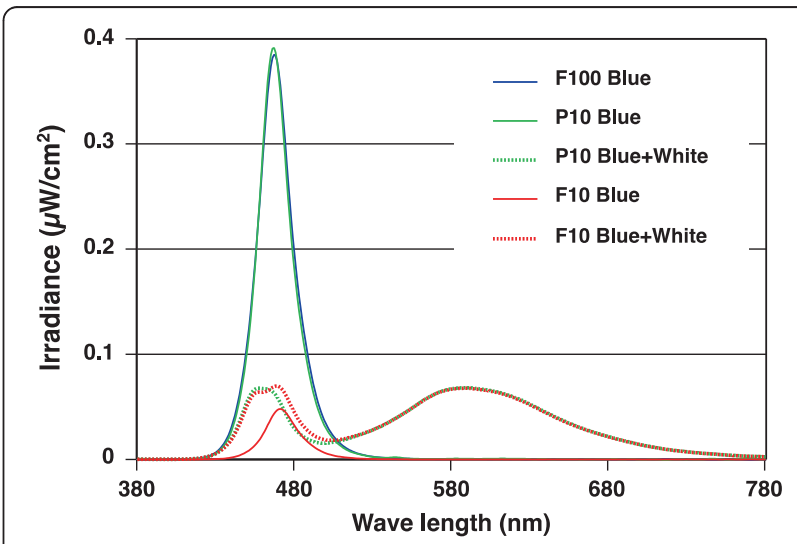

Figure 3 Spectral irradiance of each light condition. The spectral irradiance of blue LEDs in F100 condition (F100 Blue), blue LEDs in P10 condition (P10 Blue), blue and white LEDs in P10 condition (P10 Blue + White), blue LEDs in F10 condition (F10 Blue), and blue and white LEDs in F10 condition (F10 Blue + White) are shown. LED: light-emitting diode. 
Table 1 Characteristics of each light condition

\begin{tabular}{|c|c|c|c|c|c|c|c|c|}
\hline \multirow{2}{*}{$\begin{array}{l}\text { Condition } \\
\text { Light-emitting diode }\end{array}$} & \multirow{2}{*}{$\frac{\text { F0 }}{\text { White }}$} & \multicolumn{3}{|c|}{ F10 } & \multicolumn{3}{|c|}{ P10 } & \multirow{2}{*}{$\frac{\text { F100 }}{\text { Blue }}$} \\
\hline & & Blue & White & Blue + White & Blue & White & Blue + White & \\
\hline Steady/pulsed* & Steady & Steady & Steady & Steady & Pulsed & & & Steady \\
\hline Duty ratio (\%) & - & - & - & - & 10 & 90 & - & - \\
\hline Peak wavelength (nm) & - & 471 & - & - & 467 & - & - & 467 \\
\hline Full-width at half-maximum (nm) & - & 24 & - & - & 23 & - & - & 23 \\
\hline Photopic illuminance $(\mathrm{I} x)$ & 37.2 & 1.27 & 33.2 & 34.5 & 8.52 & 37.1 & 34.3 & 8.92 \\
\hline Scotopic illuminance $(\mathrm{I} X)$ & 46.9 & 16.8 & 42.0 & 58.8 & 125 & 46.3 & 54.2 & 130 \\
\hline Irradiance $\left(\mu \mathrm{W} / \mathrm{cm}^{2}\right)$ & 11.6 & 1.4 & 10.4 & 11.8 & 11.2 & 11.6 & 11.6 & 11.6 \\
\hline Photon density (log photons $/ \mathrm{cm}^{2} / \mathrm{s}$ ) & 13.5 & 12.5 & 13.5 & 13.5 & 13.4 & 13.5 & 13.5 & 13.4 \\
\hline
\end{tabular}

*Steady: steady light condition, Pulsed: pulsed light condition.

The spectral irradiance of blue and white LEDs and the halogen lamp (Figure 2), and that of each light condition (Figure 3) were measured at the participant's eye level by a spectroradiometer (HSR-8100; MAKI Manufacturing, Co. Ltd., Hamamatsu, Japan). The characteristics of each light condition are shown in Table 1.

In the F10 condition, blue LEDs and white LEDs produced light simultaneously at the irradiance ratio of about 1:9. F10 Blue, shown in Table 1 and Figure 3, shows the properties when only blue LEDs were lit. The peak wavelength of F10 Blue was $471 \mathrm{~nm}$, which was different from those of F100 and P10 Blue. However, the difference was small. P10 Blue in Figure 3 and Table 1 had values that were tenfold as great as the actual measurements of the blue LED (lighted solely at 1,000 Hz with $100-\mu$ s pulse width) in consideration of $10 \%$ of the duty ratio. The peak wavelength and full-width at halfmaximum of P10 Blue were the same as those of the blue LED or F100 condition. The spectral irradiance of F10 and P10 conditions in which blue and white LEDs produced light are shown in Figure 3 as 'F10 Blue +

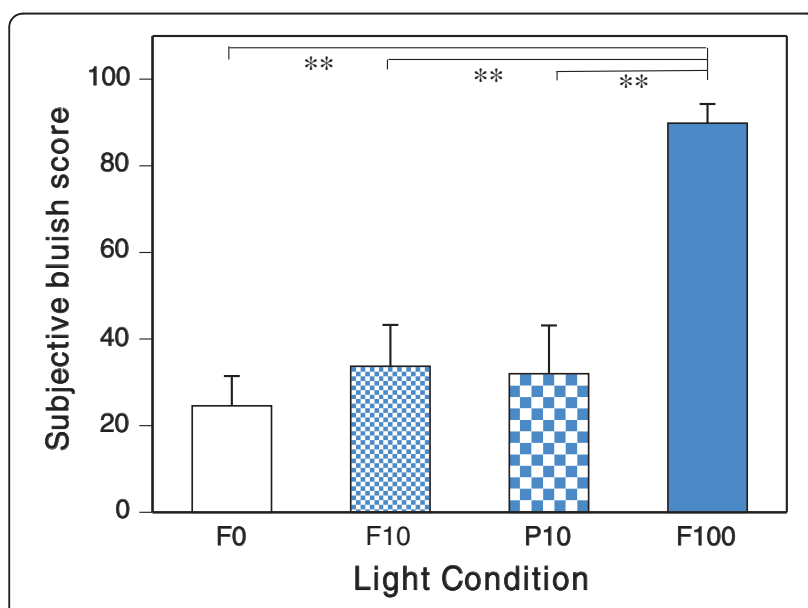

Figure 4 Subjective bluish score under F0, F10, P10 and F100 conditions (mean \pm standard error). ${ }^{* *} \mathrm{P}<0.01$.
White' and 'P10 Blue + White' respectively. The peak around 460 to $470 \mathrm{~nm}$ of F10 conditions was slightly shifted toward the long wavelength from that of the P10 condition due to the different properties of blue light.

The irradiance of all four conditions at the participant's eye level was almost the same, around $12 \mu \mathrm{W} /$ $\mathrm{cm}^{2}$, as shown in Table 1 . The photon density, photopic illumination and scotopic illumination of each light condition are also described in Table 1.

In the experiment, the participant rested for six minutes, underwent an alpha attenuation task for six minutes and then rested for three minutes in the standard illuminant condition. He then rested for nine minutes and underwent an alpha attenuation task for six minutes under each of the four lighting conditions. We measured pupil diameter (EMR-8B, nac Image Technology Inc., Tokyo, Japan) during the last three minutes of rest under the standard illuminant condition and during the nine minutes of rest for each lighting condition, and we then calculated the pupillary responses by subtracting mean values of the pupil diameter under the standard

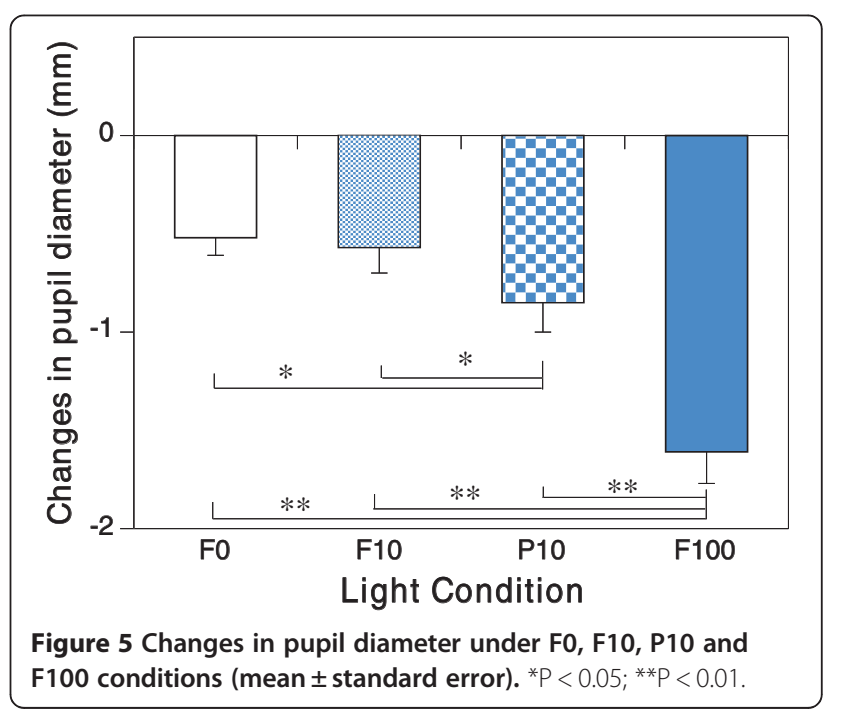


Table 2 Melanopsin-stimulating irradiance at retinal level of each light condition

\begin{tabular}{|c|c|c|c|c|c|c|c|c|}
\hline Condition & Fo & & F10 & & & P10 & & F100 \\
\hline Light-emitting diode & White & Blue & White & Blue + White & Blue & White & Blue + White & Blue \\
\hline $\begin{array}{l}\text { Melanopsin-stimulating irradiance } \\
\left(\mu \mathrm{W} / \mathrm{cm}^{2}\right)\end{array}$ & 2.29 & 1.17 & 2.06 & 3.22 & 8.84 & 2.25 & 2.91 & 9.18 \\
\hline $\begin{array}{l}\text { Melanopsin-stimulating photon density } \\
\text { (photons } / \mathrm{cm}^{2} / \mathrm{s} \text { ) }\end{array}$ & $5.65 \times 10^{12}$ & $2.89 \times 10^{12}$ & $5.08 \times 10^{12}$ & $7.97 \times 10^{12}$ & $21.8 \times 10^{12}$ & $5.57 \times 10^{12}$ & $7.19 \times 10^{12}$ & $22.7 \times 10^{12}$ \\
\hline
\end{tabular}

illuminant condition from the mean values under the experimental condition. We also analyzed data from electroencephalograms (EEGs) at $\mathrm{Fz}, \mathrm{Cz}$ and $\mathrm{Pz}$ electrode sites of the international 10-20 system, from the Kwansei Gakuin Sleepiness Scale and from the visual analog scale for subjective evaluations of sleepiness, concentration, fatigue and bluish during the experiment. One or two of the four light conditions was performed per day at the same time of day on three different days. The order of the four light conditions was counterbalanced among the participants.

One-way repeated measures analysis of variance was used to evaluate the effects of the light condition on these measurement values. When any significant effect was found, multiple comparisons of the light condition were performed by Holm's sequential Bonferroni procedure [17]. The level of statistical significance was set at 0.05 .

\section{Results and discussion}

We found that the subjective bluish score under the blue LED 100\% condition (F100) was significantly higher $(P<0.01)$ than those under other conditions. Even under the P10 condition with a $10 \%$ duty ratio of blue pulsed light of $11.2 \mu \mathrm{W} / \mathrm{cm}^{2}$ and the $\mathrm{F} 10$ condition including a steady blue LED of $1.4 \mu \mathrm{W} / \mathrm{cm}^{2}$, the participant did not perceive the light as bluish (Figure 4). No main effects of light condition on Kwansei Gakuin Sleepiness Scale score or subjective sleepiness, concentration or fatigue were found.

Change in the pupil diameter under the F100 condition was significantly greater $(P<0.01)$ than under other conditions, and showed pronounced pupillary response. Moreover, we found that the pupillary response under the P10 pulsed light condition was significantly larger $(P<0.05)$ than under the F10 and F0 conditions (Figure 5).

Changes in the EEG alpha wave band ratio at Pz under the F100 condition tended to be lower $(P<0.1)$ than under the F10 condition. There were no significant effects of light condition on the alpha attenuation coefficient.

In our study, the most important finding was that pupillary response under the P10 pulsed light condition was significantly greater than under the F10 condition, although the subjective bluish score under the P10 condition was as low as those under the F0 and the F10 conditions.

The melanopsin-stimulating irradiance and photon density at the participant's retinal level of each light condition were also estimated [18] based on the spectral absorption of the crystalline lens [19] and a template [20] indicating the spectral absorption characteristics of the photopigment with peak wavelength of $484 \mathrm{~nm}$ [6] (Table 2).

The melanopsin-stimulating irradiance and photon density at retinal level of the F10 $\left(3.22 \mu \mathrm{W} / \mathrm{cm}^{2}\right.$ and $7.97 \times 10^{12}$ photons $/ \mathrm{cm}^{2} / \mathrm{s}$ ) and the P10 conditions $\left(2.91 \mu \mathrm{W} / \mathrm{cm}^{2}\right.$ and $7.19 \times 10^{12}$ photons $\left./ \mathrm{cm}^{2} / \mathrm{s}\right)$ calculated from the multiplication values of irradiance and duration were almost the same. Despite this, the pupillary response under the P10 condition was significantly greater than under the F10 condition. This might have been due to the short $(100 \mu \mathrm{s})$ but higher melanopsin-stimulating irradiance features of the blue pulsed light of the P10 condition $\left(8.84 \mu \mathrm{W} / \mathrm{cm}^{2}\right.$ and $21.8 \times 10^{12}$ photons $\left./ \mathrm{cm}^{2} / \mathrm{s}\right)$ as compared with the blue component of the F10 condition $\left(1.17 \mu \mathrm{W} / \mathrm{cm}^{2}\right.$ and $2.89 \times 10^{12}$ photons $\left./ \mathrm{cm}^{2} / \mathrm{s}\right)$ as shown in Table 2. It has been suggested that pupillary light response is controlled by rods under lower irradiance light exposure and by ipRGCs under higher irradiance light exposure [9,14]. Panda et al. [9] reported that ipRGC contributed to the pupillary response in mice at an irradiance level greater than about $13 \log$ photons $/ \mathrm{cm}^{2} / \mathrm{s}$ of $470 \mathrm{~nm}$ light at their eye level. Takahashi et al. [14] also estimated that the irradiance level at which the role of rods in pupillary constriction was replaced by ipRGCs was around $4.54 \mu \mathrm{W} / \mathrm{cm}^{2}$ or 46.0 scotopic $\mathrm{lx}$ at the participant's eye level. In addition, it was reported from experiments on rats that the threshold retinal irradiance for depolarization of ipRGCs was about $12.7 \mathrm{log}$ photons $/ \mathrm{cm}^{2} / \mathrm{s}$ of $500 \mathrm{~nm}$ light at eye level [6]. In our study, irradiance at the eye level of P10 Blue (13.4 log photons $/ \mathrm{cm}^{2} / \mathrm{s}$ or 125 scotopic $\mathrm{lx}$ ) was greater than those values of irradiance. Because of this, we propose that the blue pulsed light of strong irradiance included in the P10 condition induced significantly greater pupillary response.

\section{Conclusion}

In the present study, we found for the first time that the pupillary response under a $100-\mu$ s pulsed blue light 
condition was significantly greater than under a steady blue light condition with equal blue light components, even though the participants did not perceive the light as bluish under these conditions.

\section{Abbreviations}

EEG: Electroencephalogram; ipRGC: Intrinsically photosensitive retinal ganglion cell; LED: Light-emitting diode.

\section{Competing interests}

The authors declare that they have no competing interests.

\section{Authors' contributions}

TK conceived and designed the study, and wrote the manuscript. YO performed the experiments, analyzed the data, and wrote the first draft. TS devised the light-control devices. TK, TS, SL, YT and YS were responsible for coordination of the study and overseeing data collection and analysis. All authors have read and approved the final manuscript.

\section{Acknowledgements}

This study was supported in part by the Grant-in-Aid for Scientific Research (B) (grant No. 23370104) from the Japan Society for Promotion of Science.

\section{Author details}

${ }^{1}$ Graduate School of Engineering, Chiba University, Chiba, Japan. ${ }^{2}$ Advanced Technology Development Center, Health and Environment Systems Group, SHARP Corporation, Osaka, Japan. ${ }^{3}$ Present address: Center for Environment, Health and Field Sciences, Chiba University, Chiba, Japan.

Received: 2 April 2012 Accepted: 17 August 2012

Published: 3 September 2012

\section{References}

1. Noguchi H, Sakaguchi T: Effect of illuminance and color temperature on lowering of physiological activity. Appl Human Sci 1999, 18:117-123.

2. Yasukouchi A, Ishibashi K: Non-visual effects of the color temperature of fluorescent lamps on physiological aspects in humans. J Physiol Anthropol Appl Hum Sci 2005, 24:41-43.

3. Katsuura T, Jin X, Baba Y, Shimomura Y, Iwanaga K: Effects of color temperature of illumination on physiological functions. J Physiol Anthropol Appl Hum Sci 2005, 24:321-325.

4. Jin $X$, Katsuura T, Iwanaga K, Shimomura Y, Inoie M: The influence of taste stimuli and illumination on electrogastrogram measurements. J Physiol Anthropol 2007, 26:191-195.

5. Ishibashi K, Kitamura S, Kozaki T, Yasukouchi A: Inhibition of heart rate variability during sleep in humans by $6700 \mathrm{~K}$ pre-sleep light exposure. J Physiol Anthropol 2007, 26:39-43.

6. Berson DM, Dunn FA, Takao M: Phototransduction by retinal ganglion cells that set the circadian clock. Science 2002, 295:1070-1073.

7. Cajochen C, Munch M, Kobialka S, Krauchi K, Steiner R, Oelhafen P, Orgul S, Wirz-Justice A: High sensitivity of human melatonin, alertness, thermoregulation, and heart rate to short wavelength light. J Clin Endocrinol Metab 2005, 90:1311-1316.

8. Brainard GC, Sliney D, Hanifin JP, Glickman G, Byrne B, Greeson JM, Jasser S, Gerner E, Rollag MD: Sensitivity of the human circadian system to shortwavelength (420-nm) light. J Biol Rhythms 2008, 23:379-386.

9. Panda S, Provencio I, Tu DC, Pires SS, Rollag MD, Castrucci AM, Pletcher MT, Sato TK, Wiltshire T, Andahazy M, Kay SA, Van Gelder RN, Hogenesch JB: Melanopsin is required for non-image-forming photic responses in blind mice. Science 2003, 301:525-527.

10. Gamlin PD, McDougal DH, Pokorny J, Smith VC, Yau KW, Dacey DM: Human and macaque pupil responses driven by melanopsin-containing retinal ganglion cells. Vision Res 2007, 47:946-954.

11. Young RS, Kimura E: Pupillary correlates of light-evoked melanopsin activity in humans. Vision Res 2008, 48:862-871.

12. Kardon R, Anderson SC, Damarijan TG, Grace EM, Stone E, Kawasaki A: Chromatic pupil responses: preferential activation of the melanopsinmediated versus outer photoreceptor-mediated pupil light reflex. Ophthalmology 2009, 116:1564-1573.
13. Tsujimura S, Ukai K, Ohama D, Nuruki A, Yunokuchi K: Contribution of human melanopsin retinal ganglion cells to steady-state pupil responses. Proc Biol Sci 2010, 277:2485-2492.

14. Takahashi Y, Katsuura T, Iwanaga K, Shimomura Y: Contribution of intrinsically photosensitive retinal ganglion cells on action spectrum for pupillary light reflex. J Illum Engng Inst Jpn 2010, 94:743-746.

15. Do MT, Yau KW: Intrinsically photosensitive retinal ganglion cells. Physio/ Rev 2010, 90:1547-1581.

16. Do MT, Kang SH, Xue T, Zhong H, Liao HW, Bergles DE, Yau KW: Photon capture and signalling by melanopsin retinal ganglion cells. Nature 2009, 457:281-287.

17. Holm S: A simple sequentially rejective multiple test procedure. Scand J Stat 1979, 6:65-70.

18. Takahashi $Y$, Katsuura T, Shimomura $Y$, Iwanaga K: Prediction model of light-induced melatonin suppression. J Light Vis Env 2011, 35:123-135.

19. Stockman A, Sharpe LT, Fach C: The spectral sensitivity of the human short-wavelength sensitive cones derived from thresholds and color matches. Vision Res 1999, 39:2901-2927.

20. Lamb TD: Photoreceptor spectral sensitivities: common shape in the long-wavelength region. Vision Res 1995, 35:3083-3091.

\section{doi:10.1186/1880-6805-31-23}

Cite this article as: Katsuura et al.: Effects of blue pulsed light on human physiological functions and subjective evaluation. Journal of Physiological Anthropology 2012 31:23.

\section{Submit your next manuscript to BioMed Central and take full advantage of:}

- Convenient online submission

- Thorough peer review

- No space constraints or color figure charges

- Immediate publication on acceptance

- Inclusion in PubMed, CAS, Scopus and Google Scholar

- Research which is freely available for redistribution 